\title{
PELATIHAN PENGOLAHAN KAKAO OLEH PRAKTISI INTERNASIONAL UNTUK MENINGKATKAN MUTU PRODUK DI KELOMPOK TANI DESA BANJAROYA, KALIBAWANG, KULON PROGO
}

\author{
Ika Restu Revulaningtyas ${ }^{1^{*}}$, Ratih Hardiyanti ${ }^{2}$, Sri Wijanarti ${ }^{3}$, Anjar Ruspita \\ Sari $^{4}$, Anjar Kistia Purwaditya ${ }^{5}$, Wildan Fajar Bachtiar ${ }^{6}$, Diklusari Isnarosi \\ Norsita $^{7}$, Satria Bhirawa Anoraga ${ }^{8}$, Iman Sabarisman ${ }^{9}$, Mohammad Affan Fajar \\ Falah $^{10}$
}

\author{
1,2,3,4,5,6,7,8,9,10 Diploma Agroindustri, Departemen Teknologi Hayati dan Veteriner, \\ Sekolah Vokasi, UGM
}

*ika.restu@ugm.ac.id

\begin{abstract}
ABSTRAK
Kelompok tani Sumber Rejeki adalah gabungan petani kakao yang dikembangkan sejak tahun 2013 dan menjadi ujung tombak Desa Kakao. Kelompok tani ini adalah mitra Pengabdian kepada Masyarakat Diploma Agroindustri pada pelatihan pengolahan kakao. Kelompok ini telah mampu memproduksi beberapa produk olahan kakao dengan menggunakan alat bantuan dari pemerintah. Produksi yang dilakukan masih berskala kecil yang menggunakan sistem pre-order. Kendala yang dihadapi adalah kurangnya pengetahuan terhadap karakteristik produk yang yang sesuai dengan preferensi pasar, belum menerapkan proses pengolahan produk olahan kakao yang baik sehingga produk tersebut belum terstandar, serta masih minimnya kemampuan untuk melakukan pengembangan produk. Untuk meningkatkan kemampuan produksi kelompok tani, maka Diploma Agroindustri mengadakan pelatihan proses pengolahan cokelat oleh praktisi internasional. Tujuan program pengabdian kepada masyarakat ini adalah kelompok tani mampu mengetahui proses pengolahan produk yang baik sehingga dapat meningkatkan mutu produk tersebut. Proses pengolahan cokelat memiliki keunikan tersendiri, di mana pembuat cokelat harus bisa mengamati dan memahami karakteristik serta perubahan cokelat selama proses pengolahannya. Keahlian ini akan meningkat seiring dengan waktu dan pengalaman yang dilakukan. Program pendampingan proses pengolahan kakao oleh praktisi internasional telah mampu melatih dan membantu kelompok tani dalam mempelajari dan mempraktikkan pengolahan cokelat melalui seminar dan praktik.
\end{abstract}

Kata Kunci: cokelat, praktik, praktisi internasional, seminar

\section{ABSTRACT}

Sumber Rejeki farmer group is a cocoa farmer group and spearhead of the Cocoa Village that were developed since 2013. This farmer group are the partner of Diploma Agroindustri in cocoa processing training. So far, this farmer group has been able to produce cocoa products using government support tools. The production is still in a small scale and it is depends on the pre order system. The constraints include this farmer group do not have knowledge about characteristics of the good products; they have not implemented a good cocoa processing so that the product is not standardized; and they do not have the ability to develop products. Diploma Agroindustri organized training about chocolate processing by international practitioner so they can improve the quality of the chocolate products. The purpose of this training is this farmer groups are able to know about the good processing of chocolate. Chocolate processing has its own uniqueness. The chocolate maker must be able to observe and understand about the characteristics and changes in chocolate during the processing. This expertise will increase over time and experience. The cocoa processing training program by international practitioner is able to train and assist farmer group in learning and practicing chocolate processing through seminar and practice.

Keywords: chocolate; practice; international practitioner; seminar 


\section{PENDAHULUAN}

Kakao (Theobroma cacao) merupakan tanaman perkebunan yang cukup penting di provinsi Daerah Istimewa Yogyakarta. Kulon Progo adalah daerah terbesar penghasil kakao dengan luas lahan yang telah terpakai untuk perkebunan komoditas kakao sebesar 2.346 ha, disusul daerah Gunung Kidul dengan luas lahan sebesar 472 ha (Badan Pusat Statistik Provinsi Daerah Istimewa Yogyakarta, 2015). Saat ini pemerintah melakukan pengembangan sentra agroindustri kakao untuk meningkatkan produksi dan nilai tambah komoditas kakao. Hal ini terlihat dari usaha Dinas Pertanian dan Pangan (DPP) Kulon Progo yang serius meningkatkan produksi kakao sejak 2011 dengan menerapkan Program Perluasan dan Peremajaan Tanaman Kakao. Program ini terbukti secara signifikan dapat meningkatkan produksi kakao dari 1.010,93 ton pada 2012 menjadi 11.460 ton pada 2015. Pengembangan sentra agroindustri kakao juga dilakukan dengan membangun setiap desa penghasil kakao menjadi sentra agroindustri pengolahan kakao yang nantinya akan dijadikan model percontohan. Pengembangan Model Desa Kakao yang dilaksanakan di Kabupaten Kulon Progo berlokasi di Desa Banjaroya, Kecamatan Kalibawang. Pengembangan Desa Kakao meliputi penanaman hingga penanganan pascapanen dengan basis pemberdayaan masyarakat dalam rangka meningkatkan nilai produk pertanian. Dengan adanya Desa Kakao diharapkan dapat menciptakan pertumbuhan ekonomi pedesaan secara optimal dan mampu berdaya saing, terintegrasi dengan usaha agroindustri mulai dari hulu sampai hilir, serta menciptakan agrowisata ataupun wisata edukasi.

Produksi kakao Indonesia sangat diperhatikan dalam perdagangan kakao dunia karena biji kakao asal Indonesia memiliki kandungan senyawa polifenol yang relatif lebih tinggi dibandingkan dengan biji kakao yang berasal dari Pantai Gading, Ghana dan Malaysia (Othman dkk., 2010). Kandungan senyawa polifenol pada kakao berkontribusi untuk menyehatkan tubuh sehingga dapat digunakan sebagai bahan pangan fungsional. Hal tersebut dapat meningkatkan daya saing kakao Indonesia di pasar internasional menjadi lebih baik. Petani kakao di Indonesia diharapkan dapat melakukan pengembangan produk olahan kakao supaya dapat meningkatkan nilai jual kakao.

Salah satu kelompok tani yang ada di Desa Banjaroya yaitu Kelompok Tani Sumber Rejeki. Kelompok tani ini menjadi salah satu kelompok tani yang masuk dalam Desa Kakao dengan lokasi di Dusun Slanden, Desa Banjaroya, Kecamatan Kalibawang, Kulon Progo atau sekitar 1 jam perjalanan dari kampus Sekolah Vokasi UGM (Gambar 1). Kegiatan utama kelompok tani ini yaitu mengelola tanaman kakao hingga diperoleh biji kakao kering. Kegiatan rutin yang biasa dilakukan adalah penanaman, pemupukan dan perawatan, pemanenan, hingga fermentasi dan pengeringan biji kakao. Setelah itu, biji kakao kering yang diperoleh biasanya dikumpulkan kemudian dijual kepada pengepul di pasar.

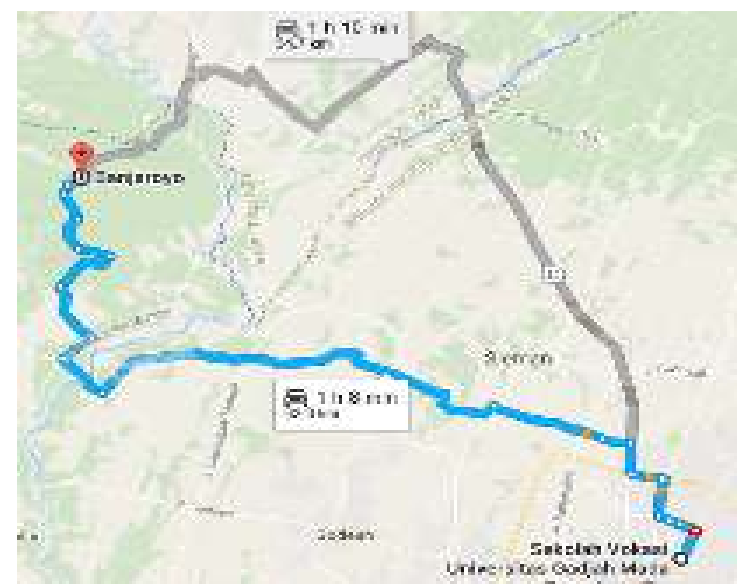

Gambar 1. Denah Lokasi Kelompok Tani Ngudi Rejeki 
Ika Restu Revulaningtyas, Ratih Hardiyanti, Sri Wijanarti, Anjar Ruspita Sari, Anjar Kistia Purwaditya, Wildan Fajar Bachtiar, Diklusari Isnarosi Norsita, Satria Bhirawa Anoraga, Iman Sabarisman, Mohammad Affan Fajar Falah Pelatihan Pengolahan Kakao Oleh Praktisi Internasional Untuk Meningkatkan Mutu Produk Di Kelompok Tani Desa Banjaroya, Kalibawang, Kulon Progo

Sejauh ini, kelompok tani dan KWT telah mampu memproduksi beberapa produk olahan cokelat dengan menggunakan alat bantuan dari pemerintah. Produksi yang dilakukan oleh kelompok tani dan KWT masih berskala kecil dan bergantung pada sistem pre-order. Kelompok tani dan KWT hanya menerima pemesanan dari pemerintah setempat guna mengikuti pameran produk daerah. Produsen belum memiliki konsumen tetap. Meskipun demikian, masih terdapat beberapa kendala yang dihadapi oleh kelompok tani dan KWT dalam menghadapi peluang pasar yang besar. Pertama, kelompok tani dan KWT belum memiliki pengetahuan terhadap karakteristik produk yang diinginkan oleh pasar. Kedua, belum menerapkan proses pengolahan produk olahan kakao yang baik sehingga produk tersebut belum dapat diterima oleh pasar. Ketiga, masih minimnya kemampuan untuk melakukan pengembangan produk.

Pengolahan sekunder kakao merupakan pengolahan biji kakao menjadi bahan setengah jadi berupa pasta, lemak, dan bubuk kakao yang kemudian dapat dimanfaatkan menjadi berbagai produk jadi misalnya makanan cokelat, minuman cokelat instan, permen, kosmetik, dan produk-produk lainnya. Proses pengolahan sekunder tersebut antara lain penyangraian, pemisahan kulit biji, pemastaan, dan pengempaan (Septianti, 2020).

Pada penelitian yang dilakukan oleh Purba, dkk (2018), hasil Importance Performance Analysis menunjukkan bahwa atribut yang perlu menjadi perhatian dalam pengembangan produk makanan cokelat adalah taste, texture, aroma, product appearance, variety, freshness, health, dan packaging. Industri pengolahan produk cokelat skala kecil menengah memiliki keterbatasan sumber daya dalam mengembangkan produknya dibandingkan dengan produsen cokelat industri besar. Oleh karena itu, industri kecil menengah perlu melakukan analisis mengenai keinginan konsumen melalui kuesioner agar produk-produk baru yang dikembangkan dapat memenuhi kebutuhan dan keinginan konsumen.

Prioritas masalah yang dihadapi oleh mitra yaitu mengenai kelompok tani dan KWT Sumber Rejeki belum memiliki pengetahuan terhadap karakteristik produk yang diinginkan oleh pasar. Masalah tersebut dapat dirumuskan sebagai berikut :

1. Bagaimana karakteristik produk olahan kakao yang diinginkan oleh pasar?

2. Bagaimana proses pengolahan produk olahan kakao yang baik sehingga produk tersebut dapat diterima oleh pasar?

3. Apa saja alternatif pengembangan produk olahan kakao yang dapat diproduksi?

4. Bagaimana cara menentukan harga jual dan promosi produk olahan kakao yang telah dapat diproduksi?

Dari permasalahan di atas, perlu diadakan sosialisasi dan pelatihan mengenai proses pengolahan produk olahan kakao oleh praktisi internasional sehingga dapat meningkatkan mutu produk yang telah dapat diproduksi oleh kelompok tani dan KWT Sumber Rejeki. Peserta pelatihan diharapkan dapat menghasilkan produk yang sesuai keinginan pasar, memiliki daya saing, dan memberi alternatif pilihan kuliner khas Kulonprogo. Harapannya, hasil dari pengabdian masyarakat kali ini bisa diperoleh beberapa produk olahan kakao sebagai komoditas unggulan Kabupaten Kulonprogo, yang nantinya dapat menjadi jalan untuk meningkatkan kesejahteraan masyarakat Kulonprogo.

\section{METODE}

Tempat dan Waktu. Kegiatan Pengabdian kepada Masyarakat dilaksanakan di Desa Banjaroya, Kecamatan Kalibawang, Kabupaten Kulon Progo. Rangkaian kegiatan 
dilaksanakan mulai bulan Juni sampai November 2019.

Khalayak Sasaran. Khalayak sasaran kegiatan Pengabdian kepada Masyarakat adalah kelompok tani Sumber Rejeki, Banjaroya, Kalibawang, Kulon Progo.

Metode Pengabdian. Metode yang digunakan ini terbagi menjadi empat tahap, yaitu survei lokasi dan diskusi dengan kelompok tani, uji coba pembuatan cokelat di laboratorium, pelatihan dan sosialisasi, serta evaluasi. Survei yang dilakukan merupakan kegiatan monitoring rutin dari kegiatan pengabdian masyarakat sebelumnya yang dilakukan di Desa Banjaroya, Kecamatan Kalibawang, Kabupaten Kulonprogo, Daerah Istimewa Yogyakarta. Survei dan konsultasi dengan masyarakat ini adalah langkah awal untuk menentukan masalah utama masyarakat penghasil kakao. Dari survei awal ini pelaksana kegiatan dapat melihat sejauh mana petani kakao dapat melakukan pengolahan sekunder kakao dengan metode sederhana atau tradisional, sekaligus melihat kontinuitas produksi olahan sekunder tersebut. Melalui konsultasi dengan kelompok tani di Desa Banjaroya, pelaksana kegiatan dapat mengetahui kendala yang dialami selama proses pengolahan sekunder kakao (bubuk kakao) serta apakah masyarakat telah dapat menjual dan melakukan pengembangan produk dari olahan kakao tersebut. Selanjutnya dilakukan uji coba pembuatan cokelat menggunakan peralatan pengolahan kakao yang dimiliki oleh Program Studi Agroindustri tersebut. Hasil uji coba digunakan untuk melaksanakan pelatihan dan sosialisasi pembuatan cokelat yang didampingi oleh seorang expert cokelat dari Belgia (Mr. Willy Geeraerts).

Indikator Keberhasilan. Indikator keberhasilan kegiatan Pengabdian kepada Masyarakat di Desa Banjaroya, Kecamatan Kalibawang, Kabupaten Kulon Progo adalah peserta mampu mengetahui proses pengolahan cokelat yang baik serta mampu meningkatkan mutu produk cokelatnya. Selain itu, peserta pelatihan juga memiliki dokumen mengenai proses pengolahan cokelat yang telah dilakukan pada saat pelatihan menggunakan peralatan pengolahan kakao yang dimiliki oleh Program Studi Agroindustri.

Metode Evaluasi. Evaluasi terhadap kegiatan Pengabdian kepada Masyarakat dilakukan melalui sosialisasi dan diskusi antara pelaksana kegiatan dengan kelompok tani Sumber Rejeki. Evaluasi dilakukan untuk mengatasi kendala atau permasalahan yang muncul. Evaluasi kegiatan ini dilakukan untuk memperoleh masukan dari khalayak sasaran untuk perbaikan kegiatan Pengabdian kepada Masyarakat pada periode selanjutnya.

\section{HASIL DAN PEMBAHASAN}

Kakao adalah salah satu komoditas unggulan di Indonesia. Kakao telah diolah menjadi berbagai jenis makanan dan minuman yang sangat bervariasi. Sebagai negara pengekpor biji kakao terbesar ketiga di dunia, Indonesia mensuplai 387,8 ribu ton ke pasar dunia (Pusat Penelitian Kakao dan Kopi Indonesia, 2015). Industri pengolahan kakao masih kecil apabila dibandingkan dengan jumlah bahan bakunya (biji kakao). Apabila dilihat dari aspek nilai tambahnya, biji kakao kering merupakan produk kakao dengan nilai tambah yang paling rendah. Pengolahan biji kakao menjadi produk primer mampu meningkatkan nilai tambah kakao secara signifikan. Tantangan terbesar yang harus dihadapi untuk dapat bersaing dengan produk yang ada di pasar adalah kualitas produk kakao dan turunannya.

Proses pengolahan biji kakao merupakan faktor penting dalam menentukan mutu produk akhir cokelat. Setelah kakao matang dipanen maka tahapan awal pengolahannya adalah membelah buah kakao untuk mengeluarkan bijinya. Biji kakao kemudian difermentasikan di dalam kotak selama kurang lebih satu minggu dan setelah itu biji dimasukkan ke dalam 
Ika Restu Revulaningtyas, Ratih Hardiyanti, Sri Wijanarti, Anjar Ruspita Sari, Anjar Kistia Purwaditya, Wildan Fajar Bachtiar, Diklusari Isnarosi Norsita, Satria Bhirawa Anoraga, Iman Sabarisman, Mohammad Affan Fajar Falah Pelatihan Pengolahan Kakao Oleh Praktisi Internasional Untuk Meningkatkan Mutu Produk Di Kelompok Tani Desa Banjaroya, Kalibawang, Kulon Progo

proses pengeringan. Selanjutnya, biji kakao akan melewati proses penyangraian, dipisahkan antara kulit dan bijinya kemudian dihancurkan menjadi bagian kecil yang disebut sebagai daging biji (nib). Daging biji ini kemudian digiling sehingga menghasilkan pasta cokelat yang kental dan mengandung lemak cokelat. Dari pasta cokelat tersebut kemudian dipisahkan antara lemak dan bungkilnya yang dapat diolah lagi menjadi bermacam produk cokelat lainnya (Hatmi dan Sinung, 2012).

Cokelat merupakan produk olahan kakao yang pengelompokannya dalam kategori pangan cukup kompleks. Peredaran produk cokelat di pasaran tidak dapat dibedakan antara cokelat dengan cokelat imitasi, padahal keduanya memiliki komposisi yang berbeda. Cokelat pada dasarnya dibagi menjadi dua kelompok yaitu cokelat dan cokelat imitasi. Cokelat pada umumnya terbuat dari bahan baku yang berasal dari kakao dan dapat ditambahkan dengan bahan pangan lain. Produk kakao yang digunakan dalam pembuatan cokelat adalah kakao massa, kakao bubuk, dan/atau lemak kakao (Badan Pengawas Obat dan Makanan, 2017).

Produsen cokelat pada umumnya memproduksi tiga macam cokelat jadi, yaitu cokelat pekat (dark chocolate), cokelat susu (milk chocolate), dan cokelat putih (white chocolate). Ketiga macam cokelat ini dibedakan berdasarkan komposisinya, yaitu dari kandungan cokelat, gula, serta bahan tambahan lain. Selain itu, juga terdapat cokelat jenis couverture yang merupakan cokelat premium yang sering digunakan untuk membuat pastry ataupun untuk membuat kue (Hatmi dan Sinung, 2012).

Program Studi Agroindustri memiliki peralatan pengolahan kakao. Peralatan pengolahan kakao ini digunakan pada kegiatan pelatihan kelompok Tani Sumber Rejeki. Selama ini peralatan tersebut digunakan untuk mengolah kakao dan mengembangkan produk olahan kakao, seperti cokelat batang dan cokelat bubuk. Pendampingan praktisi internasional bertujuan untuk meningkatkan mutu produk cokelat yang dihasilkan serta mengoptimalkan efisisensi mesin yang digunakan. Kegiatan ini diawali dengan adanya uji coba pembuatan cokelat menggunakan peralatan pengolahan kakao yang dimiliki oleh Program Studi Agroindustri tersebut (Gambar 2).

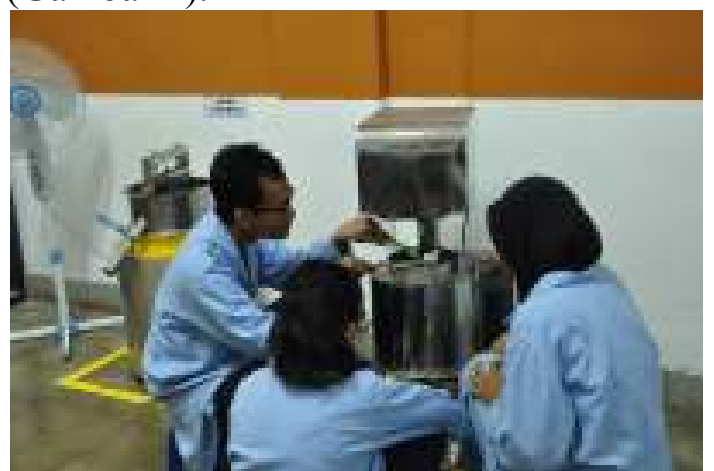

Gambar 2. Uji Coba Pembuatan Cokelat

Pelatihan dan sosialiasi bertujuan untuk meningkatkan pengetahuan dan kemampuan dari peserta program $\mathrm{PkM}$ dalam mengetahui karakteristik produk olahan kakao yang diharapkan konsumen serta bagaimana cara meningkatkan mutu produk olahan kakao sehingga dapat diterima oleh pasar. Sosialisasi kali ini difokuskan pada bagaimana cara pengolahan kakao menjadi produk cokelat yang benar sehingga dapat menghasilkan produk yang bisa bersaing dengan produk yang ada di pasaran. Proses pengolahan cokelat memiliki keunikan tersendiri, di mana pembuat cokelat harus bisa mengamati dan memahami karakteristik serta perubahan cokelat selama proses pengolahannya. Keahlian ini akan meningkat seiring dengan waktu dan pengalaman yang dilakukan.

Kegiatan yang telah dilakukan adalah memadukan antara penyampaian materi di kelas (workshop) dan pelatihan di laboratorium (Gambar 3). Pada sesi workshop, Mr. Willy Geeraerts menyampaikan teori mengenai cara pengolahan cokelat. Selain itu, pada sesi workshop ini juga disampaikan 
pengalaman dari praktisi yang merupakan manajer produksi PT Pagilaran. Pada hari berikutnya dilakukan pelatihan yang didampingi langsung oleh Mr. Willy Geeraerts. Pelatihan ini menekankan pada penerapan dasar-dasar pengolahan kakao, prinsip kerja mesin pengolah kakao, serta pengembangan metode dalam mengolah kakao. Peserta workshop dan pelatihan ini adalah kelompok tani Sumber Rejeki, UKM, dan masyarakat umum yang berminat dalam pengolahan kakao skala kecil.
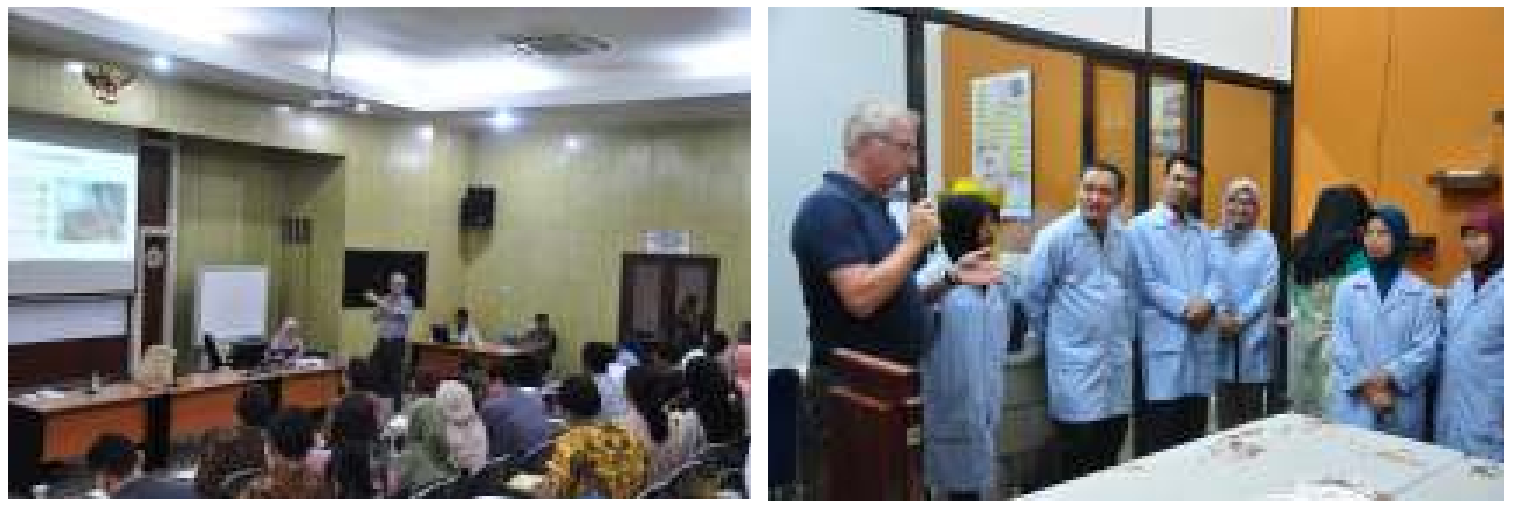

Gambar 3. Kegiatan Seminar dan Workshop

Pelatihan dan sosialisasi yang dilaksanakan telah menghasilkan 2 prototipe produk cokelat, yaitu Dark Chocolate dan Milk Chocolate. Prototipe ini masih dalam tahap pengembangan lebih lanjut untuk mendapatkan hasil yang lebih baik. Selain itu, pelatihan ini juga menghasilkan pedoman pembuatan cokelat beserta pengembangan produk yang telah disusun untuk melakukan standardisasi proses dan mutu produk yang dihasilkan. Dasar dalam melakukan pengembangan produk adalah bahwa produsen harus memahami nilai-nilai yang dianggap penting oleh konsumen dan mampu memunculkan nilai-nilai tersebut melalui kombinasi antar atribut sehingga dapat memberikan kesan positif secara psikologis (Kottler dan Armstrong, 2004).

Pengembangan produk merupakan usaha untuk mengembangkan sebuah produk yang sama sekali baru maupun pengembangan terhadap produk yang sudah ada di pasar. Dalam kasus ini, pengembangan produk dilakukan dengan mengembangkan produk yang sudah ada di pasar melalui proses benchmarking dengan memanfaatkan bahan baku kakao yang dihasilkan oleh kelompok tani kakao Desa Banjaroya. Perencanaan produk adalah proses menciptakan ide produk dan menindaklanjuti sampai produk diperkenalkan ke pasar. Desain produk yang baik, harus memenuhi 3 (tiga) aspek penting yang sering disebut segitiga aspek produk, yaitu kualitas yang baik, biaya rendah, dan jadwal yang tepat. Dalam mendesain suatu produk, harus memperhatikan secara detail tentang fungsi-fungsi dari produk yang didesain (David dan Hammond, 1995).

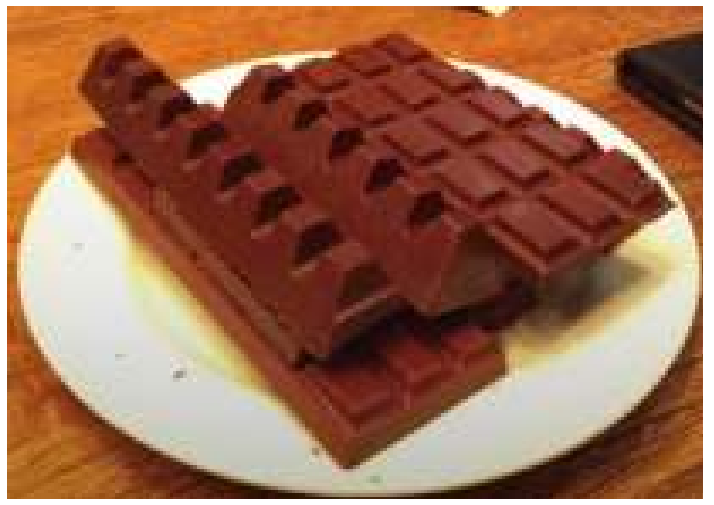

Gambar 4. Produk Hasil Pelatihan

Berdasarkan sosialisasi dan pelatihan yang telah dilakukan kepada masyarakat maka hasil yang dicapai adalah masyarakat desa Banjaroya, khususnya anggota kelompok tani 

Pelatihan Pengolahan Kakao Oleh Praktisi Internasional Untuk

Sumber Rejeki, kegiatan Pengabdian kepada Masyarakat tersebut mampu melatih dan membantu kelompok tani dalam mempelajari, mempraktikkan, dan mengembangkan pengolahan cokelat.

Kuesioner dan lembar evaluasi diberikan kepada peserta pelatihan. Dari kuesioner dan lembar evaluasi yang telah diberikan, pelaksana kegiatan memperoleh saran dan masukan terkait pelaksanaan kegiatan Pengabdian kepada Masyarakat ini. Berdasarkan kuesioner yang diberikan sesudah kegiatan pelatihan, terlihat bahwa ada peningkatan pengetahuan dan keterampilan dari anggota kelompok tani terkait proses pengolahan biji kakao menjadi produk cokelat. Peningkatan pengetahuan ini dapat disebabkan oleh adanya seminar dan praktik langsung sehingga peserta dapat langsung menyerap materi yang diberikan (Retnawati, Widajanti, dan Nugrahaeni, 2014). Peserta menyampaikan bahwa kegiatan ini sangat bermanfaat dan harapannya program ini masih terus berlanjut hingga kelompok tani dapat melakukan pengembangan produk berbahan dasar biji kakao.

Evaluasi dilakukan berdasarkan hasil pendampingan masyarakat saat sosialisasi dan pelatihan. Evaluasi dilakukan untuk mengatasi kendala atau permasalahan yang muncul. Evaluasi ini diharapkan dapat diatasi pada tahun ini maupun dilakukan pengembangan dan modifikasi dalam tindak lanjutnya. Dengan demikian, pengembangannya dapat dimanfaatkan untuk program pengabdian masyarakat selanjutnya.

\section{SIMPULAN}

Program Pengabdian kepada Masyarakat berupa sosialisasi dan pelatihan proses pengolahan kakao oleh praktisi internasional mampu melatih dan membantu kelompok tani Sumber Rejeki dalam mempelajari dan mempraktikkan pengolahan cokelat melalui seminar dan praktik. Pihak mitra mendapatkan pengetahuan dan keterampilan terkait cara membuat produk cokelat. Selain itu, pihak mitra menghendaki adanya keberlanjutan program sehingga kelompok tani mampu mengembangkan produk olahan kakao secara mandiri dan berkelanjutan.

\section{DAFTAR PUSTAKA}

Badan Pengawas Obat dan Makanan, 2017. Pedoman Cokelat. Direktorat Standardisasi Produk Pangan Deputi Bidang Pengawasan Keamanan Pangan dan Bahan Berbahaya Badan Pengawas Obat dan Makanan Republik Indonesia. Jakarta Pusat.

Badan Pusat Statistik Provinsi Daerah Istimewa Yogyakarta, 2015. Daerah Istimewa Yogyakarta Dalam Angka 2014 : Potensi Kakao di Daerah Istimewa Yogyakarta. Yogyakarta.

David, I dan Hammond, J. 1995. Pengembangan Produk. Penerjemah Mariani Gandamiharja. Pustaka Binaman Pressindo. Jakarta.

Hatmi, Retno Utami., dan Sinung Rustijarno, 2012. Teknologi Pengolahan Biji Kakao Menuju SNI Biji Kakao 01-2323-2008. Balai Pengkajian Teknologi Pertanian. Yogyakarta.

Kottler, P dan G. Armstrong. 2004. Principles of Marketing. 10th edition Pearson Prentice Hall.

Othman, A., A.M.M. Jalil, K.K. Wang, A. Ismail, N.A. Ghani and I. Adenan. 2010. Epicatechin Content and Antioxidant Capacity of Cocoa Beans From Four Different Countries. African Journal of Biotechnology 9 (7) : 1052-1059.

Purba, Humiras Hardi, M. Syamsul Maarif, Indah Yuliasih, dan Aji Hermawan. 2018. Pengembangan Produk Makanan Cokelat Berbasis Preferensi Konsumen. Jurnal Teknologi Industri Pertanian 28 (1) : 40-47.

Pusat Penelitian Kakao dan Kopi Indonesia. 2015. Kakao : Sejarah, 
Botani, Proses Produksi, Pengolahan, dan Perdagangan. Gadjah Mada University Press. Yogyakarta.

Retnawati, S., Widajanti, L., dan Nugrahaeni, S. (2014). Pengaruh Pelatihan dengan Metode Simulasi terhadap Keberhasilan Penerapan Makan Beraneka Ragam oleh Kader Pendamping (Studi di Kecamatan Trawas Kabupaten Mojokerto). Jurnal Manajemen Kesehatan Indonesia : 212-220.

Septianti, Erina. 2020. Teknologi Pengolahan Primer dan Sekunder Biji Kakao. http://www.litbang.pertanian.go.id/ Diakses pada 12 Agustus 2020. 